\title{
NUTRITIONAL STATUS AND FOOD CONSUMPTION PATTERNS OF YOUNG CHILDREN LIVING IN WESTERN UGANDA
}

\author{
A. BRIDGE, W. KIPP, K. RAINE and J. KONDE-LULE
}

\begin{abstract}
Objectives: The aim of this pilot study was to compare the nutritional status and food consumption patterns of children under five years.

Design: Quantitative, exploratory, cross sectional study.

Setting: Kabarole district, western Uganda. Kabarole district is a rural district with subsistence farming as the main income.

Subjects: Two hundred and five children between 12 and 72 months of age living in AIDS affected homes versus children living in non-AIDS affected homes were examined.

Results: Fifty-five percent of all children were stunted and $20.5 \%$ were underweight. There was no difference in the prevalence of malnutrition between children living in AIDS affected homes versus non-AIDS affected homes. Only children between 12-35 months suffered from a daily deficit in caloric intake. The older children consumed the basic recommended daily intake (RDI) for protein, fat, iron and vitamin A. Due to frequent disease episodes and limitations in the estimations of individual total energy expenditure, the results are likely underestimations of the children's true nutritional requirements. The type of foods given to children in AIDS affected homes and controls were quite similar.

Conclusion: Young children in Kabarole district suffer from severe chronic malnutrition rates, but rates and feeding patterns are not different in AIDS affected versus non AIDS affected homes.
\end{abstract}

\section{INTRODUCTION}

Overall, the health of children in Uganda is less than optimal. Child mortality is estimated to be 147 deaths per 1000 live births as a result of malaria $(25 \%)$, anaemia $(14 \%)$, pneumonia $(10 \%)$ and diarrhoea $(13 \%)$. The child mortality rate is $25 \%$ higher than expected which has been attributed to HIV / AIDS) (1,2). Adetunji and Wekesa indicate that the effects of the HIV/AIDS epidemic has had a profound effect on the health of children, directly through infant and child HIV infection, and indirectly through the effects of AIDS on the social and economic functioning of families, communities and on the country as a whole $(3,4)$.

In Uganda, malnutrition is estimated to contribute to $40 \%$ of all child deaths $(5,6)$.

It has been documented that the rates of malnutrition in western Uganda (especially northwest Uganda) are significantly higher than in the country as a whole, and they appear to be increasing (7). In 2000 the national rate of stunting was $39.1 \%$ while stunting in the western region was $48 \%$ (8). 1t has been demonstrated that HIV / AIDS depletes family resources over time, thus impacting directly child nutrition (9). Indirectly, a chronically 
ill parent may not be able to provide proper childcare and may have fewer resources available to provide basic needs such as food and health care for the children. Malnutrition has been proven to impact child morbidity, mortality, growth and development. It is important to identify populations at increased risk of malnutrition and to highlight the great need for programmes and policies aimed at improving the nutritional status of children.

The purpose of this study was to measure and compare the nutritional status of children between 12 to 72 months of age living in households where one adult parent was affected by clinical AIDS versus those children in the same age group living in households headed by parents not affected by AIDS. The study was carried out in Fort Portal town and various surrounding sub-counties, located in Kabarole district, western Uganda. The data collection took place from September to November 2003. The study presented here was part of a larger study with detailed anthropometric measurements in children of the two groups of households. Part of the results from this study are presented elsewhere (10). The focus of this article is to describe the food consumption patterns of the children in AIDS affected households and controls, determine any food deficiencies and compare feeding practices in both groups.

\section{MATERIALS AND METHODS}

The study was a quantitative, exploratory, cross sectional study. Subjects included children between 12 and 72 months of age and their primary caregiver. Children were recruited into the study by: (a) selecting children who were living in homes where at least one parent or adult family member suffered from AIDS and needed family care, and (b) selecting children and their primary caregiver who were living in homes where adult family members were not suffering from AIDS. Children under one year of age were excluded based on the assumption that they were likely to be breastfed, and therefore less likely to be malnourished. Children with HIV / AIDS were also excluded based on the assumption that they were likely to be ill and malnourished as a result of the HI V / AIDS disease process. AIDS in children was only diagnosed clinically, as no laboratory investigations were undertaken.
One hundred and five AIDS affected households were identified from the Kabarole home-based care list and lists of AIDS patients known to have accessed HIV/AIDS support services. An HIV/ AIDS affected household was defined as a home, where one adult family member suffers from clinical AIDS and requires family care at home. One hundred controls (non-AIDS affected homes) were selected from the nearest neighbouring households to the sampled AIDS affected home, and were identified by the community leaders or local chairpersons as a known non-AIDS affected home.

A survey questionnaire and anthropometric measures for children aged 12 to 72 months were the instruments of data collection. The survey of 76 questions was administered to the primary caregiver of the child and was used to collect quantitative and qualitative data on the following areas of interest: demographic information of the principal caregiver for the children, recent disease episodes and a food frequency questionnaire, which assessed the frequency and quantity of common foods consumed by each child. Food frequency questionnaires contained two parts: a list of relevant, common foods such as basic sources of carbohydrates, protein, fats, vitamin $A$ and iron, and a response section indicating the frequency of consumption and portion size. This list of main foods was compiled with the help of the District Health Team Members including a nutritionist and other knowledgeable persons. Portion size was estimated to be a multiple of a specified quantity, or based on a common, standard plastic measuring cup.

In order to analyse the food frequency results, an estimated total energy expenditure (TEE) was calculated for each individual child. TEE consists of the energy required to meet the basal metabolic rate, diet induced thermo genesis, plus activity and growth (11). TEE is based on an individual's age, weight and activity level, and assumes the individual is healthy and free of disease. Secondly, the average daily intake of consumed foods was compiled by analysing the average daily servings, weekly servings and average serving sizes for boys and girls aged 12 to 35 months and 35 to 72 months. Finally, the total average energy and nutrient intake of the children were compared to data in food consumption tables compiled by Savage-King and Burgess (12). In addition, food consumption patterns 
of children were compared in both types of households in the following way: (a) it was assessed, whether a specific food was eaten by the children in an HIV / AIDS affected home and in controls, (b) for foods eaten in both types of households, the daily servings were estimated and compared.

The age of the child was obtained by caregiver recall of the month and year the child was born, or by proof from birth documentation when available. Weights of children were measured by Salter spring balance for children who were not able to stand, and by Seca (trade mark) Unicef Electronic Standing Scale 890 for those who could stand. The scales measured up to increments of 100 grams as per WHO guidelines on recommended measurement protocols (13). Height was measured by a vertical measuring rod and length board with a moveable head board of $100 \mathrm{~cm}$ with increments capable of measuring to an accuracy of $0.5 \mathrm{~cm}$. The children were measured barefoot. Children who could not stand were measured by the same measuring rod, but while lying on the ground. Height and weight were measured twice by two independent examiners. Children were also clinically assessed for signs of clinical malnutrition such as marasmus and Kwashiorkor.

Proportions were analysed using the Pearson Chi-Square test or Fisher's exact test with a significance level of 0.05 . The median number of food servings was between one and two per day, which did not constitute enough variability to make a meaningful statistical analysis.

The study was approved by the Health Research Ethics Board at the University of Alberta and by the
District Director of Health Services, Fort Portal, Uganda. Each principal caregiver of a child was informed about the study and signed a consent form. Identification numbers were assigned to each subject to keep them anonymous. None of the selected participants refused to be part of the study.

\section{RESULTS}

Educational levels and earning power in the households were low. Twenty nine percent of principal caregivers for the children had received no formal education while $56 \%$ had achieved primary level education and only $3 \%$ had achieved full secondary/university education. In terms of occupation, $45 \%$ practiced subsistence agriculture, $40 \%$ were average level farmers (occasionally selling agricultural products on the market) and $15 \%$ were involved in an occupation of higher status such as running a business, selling goods and providing services to the public. The study indicated to us that there was widespread poverty in the area, which is typical for this district.

Results from anthropometry showed that $55.1 \%$ (95\% Cl: $48.3,61.9)$ of surveyed children were stunted ( $\leq 2 \mathrm{Z}$-scores height for age). Of these, $24.4 \%$ (95\% CI: $18.5,30.3)$ of children were considered severely stunted ( $<3 \mathrm{Z}$ scores height for age). The prevalence of children classified as underweight ( $\leq 2$ Z-scores weight for age) was 20.5\% (95\% CI: 15.0, 26.0), and $2.0 \%(95 \% \mathrm{Cl}: 0.1,3.9)$ were severely underweight ( $<3 \mathrm{Z}$-scores weight for age). Detailed information on the nutritional status of the children by age and gender is displayed in Table 1 .

\section{Table 1}

Nutritional status of children by age and sex $(n=205)$, mean $z$-scores and standard deviation (in bracket)

\begin{tabular}{lcccccc}
\hline Age (months) & \multicolumn{3}{c}{ Males $(\mathrm{n}=104)$} & \multicolumn{3}{c}{ Females $(\mathrm{n}=101)$} \\
& Weight for & Height for & Weight for & Weight for & Height for & Weight for \\
& age & age & height & age & age & height \\
\hline $12-23$ & $-0.90(1.55)$ & $-2.40(1.56)$ & $0.35(0.86)$ & $-0.92(1.38)$ & $-2.40(1.23)$ & $0.35(0.94)$ \\
$24-35$ & $-0.76(1.24)$ & $-2.02(1.60)$ & $0.50(0.86)$ & $-1.05(1.14)$ & $-2.31(1.37)$ & $0.35(0.80)$ \\
$36-47$ & $-0.96(1.04)$ & $-2.57(1.75)$ & $0.67(0.86)$ & $-1.08(1.24)$ & $-2.03(1.67)$ & $0.33(0.89)$ \\
$48-59$ & $-1.24(0.89)$ & $-2.28(1.00)$ & $0.21(1.09)$ & $-0.77(1.27)$ & $-1.65(1.30)$ & $0.36(1.17)$ \\
$60-72$ & $-0.75(1.06)$ & $-1.84(1.31)$ & $0.53(0.90)$ & $-0.80(0.90)$ & $-1.96(1.29)$ & $0.53(1.16)$ \\
\hline
\end{tabular}


It is important to note that we did not find any clinical case of Kwashiorkor, but seven cases of mild marasmus (four boys, three girls). Two lived in nonAIDS affected homes, while five lived in AIDS affected homes which did not constitute a significant difference $\left(x^{2}=1.074 p=0.239\right)$. None of the children had a Z score of $<2$ for height for weight (wasting). Wasting was used as defined by the World Health Organization which describes it as a significant loss in weight attributable to acute starvation or severe disease process (13).

The common foods consumed by the children under study were grouped into starches, protein and fat. The most common source of starch was matoke (cooking banana). Beans were the main source of protein. Ground-nut sauce also provided protein, but was less frequently consumed. Animal protein contributed to a small percentage of the total protein intake and eggs were rarely eaten. The majority of children consumed milk. Children received fats from small amounts of cooking oil/lard and avocado. Children's main source of fruits and vegetables were avocados and green vegetables. The lack of yellow fruits in the diets of the children could be attributed to the rainy season (September-November), when fruits such as mangoes were not available.

The majority of children ate two main meals a day with occasional snacks. Matoke was eaten twice a day accented by beans and green vegetables. Beans are consumed by $96.5 \%$ of younger children (12-34 months) and by $98 \%$ of older children (35-72 months) approximately twice a day. Green vegetables are typically eaten once a day, seven days a week. Cooking oil/fat is used by the majority of families, approximately twice a day, seven times a week for children aged 12 to 35 months and only five times a week for children aged 35 to 72 months of age.

Common snack foods were bread, milk, and avocado. Milk appeared to be commonly consumed by $81.4 \%$ of younger children on average twice a day, every day. Only $68 \%$ of older children drank milk on average once a day, every day. Seventy four percent of older children (ages 36 to 72 months) consumed groundnut sauce for one meal, approximately four times a week. Eighty three percent of younger children consumed ground-nut sauce, but only for one meal, approximately three times a week.

Animal protein was not often consumed, as it had to be purchased in most homes. Generally, families strive to eat meat once a week, such as fish, or red meat. Fish was only eaten once to twice a week. Only $34 \%$ of young children and $28 \%$ of older children ever ate fish. Seven percent of young children consumed chicken as it is the most expensive animal protein, and only $1.7 \%$ of older children ate chicken. If chicken was consumed it was for one meal usually once a week. Red meat was more commonly consumed as $70 \%$ of young children and $56 \%$ of older children were cited to eat one meal with meat approximately one to two times a week.

The average TEE (kcal/day) for children aged 12 to 35 months was calculated to be $1488 \mathrm{kcal} /$ day (SD=300, range $679 \mathrm{kcal} /$ day to $1962 \mathrm{kcal} /$ day). Children aged 12 to 35 months did not consume the recommended daily intake (RDI) of calories based on their compiled food frequency data, but they did appear to consume the above recommended daily intake (RDI) of protein, fat, iron and vitamin A which results in a deficient intake of carbohydrates (Table 2).

Children aged 36 to 72 months had an estimated TEE (kcal/day) of $1520 \mathrm{kcal} /$ day (SD=328, range 789 $\mathrm{kcal} /$ day to $3714 \mathrm{kcal} /$ day). On average, older children consumed an extra $110 \mathrm{kcal}$ a day based on the average compiled total daily portions from their food frequency questionnaires. They also appeared to consume the recommended daily intake of protein, fat, iron and vitamin A (Table 3).

There were no statistically significant differences between the diets of children aged 12-35 months living in AIDS affected and non-AIDS affected homes. The only exceptions were noted in the consumption of millet. Ninety percent of children in AIDS affected homes ate millet, while $71.7 \%$ of children in non-AIDS affected homes consumed millet in their diet at least once a month $\left(x^{2} 4.95\right.$, $\mathrm{p}=0.026$ ). Ninety five percent of children (aged 12 to 35 months) in AIDS affected homes consumed meat in their diets while only $80 \%$ of children of the same ages in non-AIDS affected homes consumed meat in their diet $\left(x^{2} 4.4, \mathrm{p}=0.036\right)$. In children aged 36 to 72 months, ninety three percent of children in non-AIDS affected homes ate avocadoes while $100 \%$ of children in AIDS affected homes ate avocadoes $\left(x^{2} 4.8, p=0.028\right)$. Seventy two percent of children in non-AIDS affected homes ate meat at least once a month compared to $87.5 \%$ of children in AIDS affected homes $\left(\mathrm{x}^{2} 4.1, \mathrm{p}=0.042\right)$. When the number of daily servings of the food consumed was compared between HIV / AIDS affected homes and HI V / AIDS negative controls, children in both type 
Table 2

Estimation of average daily nutritional intake based on food frequency results for children aged 12-35 months $(n=86)$

\begin{tabular}{|c|c|c|c|c|c|c|c|}
\hline $\begin{array}{l}\text { Food } \\
\text { groups }\end{array}$ & Type of food & $\begin{array}{l}\text { Total daily } \\
\text { portion }(\mathrm{g})\end{array}$ & Kcal & Protein $(\mathrm{g})$ & Fat $(\mathrm{g})$ & Iron (mg) & $\begin{array}{c}\text { Vitamin A } \\
\quad(\mathrm{RE})\end{array}$ \\
\hline \multirow[t]{5}{*}{ Starch } & Cassava & 20 & 30 & 0.2 & 0.04 & 0.3 & 1.0 \\
\hline & Matoke & 260 & 340 & 3.2 & 0.08 & 5.2 & 0.0 \\
\hline & Bread & 20 & 80 & 0.7 & 4.0 & 0.3 & - \\
\hline & Millet & 30 & 90 & 1.5 & 0.4 & 1.4 & 1.0 \\
\hline & Beans & 170 & 220 & 15.2 & 0.9 & 5.7 & - \\
\hline \multirow[t]{3}{*}{ Protein } & Ground-nut sauce & 50 & 140 & 6.4 & 11.5 & 1.0 & 1.4 \\
\hline & Meat & 7 & 20 & 1.3 & 1.3 & 0.3 & 1.8 \\
\hline & Milk & 220 & 150 & 7.8 & 8.2 & 0.1 & 115 \\
\hline Fat & Cooking oil & 1 & 100 & 0.0 & 11.3 & 0.0 & 0.0 \\
\hline Fruit, & Avocado & 100 & 120 & 1.4 & 11.0 & 1.4 & 88 \\
\hline \multirow[t]{4}{*}{ Vegetables } & Green vegetables & 30 & 50 & 3.6 & 0.06 & 0.6 & 314 \\
\hline & & Totals & 1340 & 41.0 & 49.0 & 16.0 & 522 \\
\hline & & ${ }^{*}$ RDI & 1500 & 23 & 35 & 13 & 400 \\
\hline & & Balance & -160 & 18 & 14 & 3 & 122 \\
\hline
\end{tabular}

${ }^{*}$ RDI $=$ Recommended Daily Intake

Table 3

Estimation of average daily nutritional intake based on food frequency results for children aged 36-72 months $(n=166)$

\begin{tabular}{|c|c|c|c|c|c|c|c|}
\hline $\begin{array}{l}\text { Food } \\
\text { groups }\end{array}$ & Type of food & $\begin{array}{l}\text { Total daily } \\
\text { portion }(\mathrm{g})\end{array}$ & Kcal & Protein $(\mathrm{g})$ & Fat (g) & Iron (mg) & $\begin{array}{c}\text { Vitamin A } \\
\text { (RE) }\end{array}$ \\
\hline \multirow[t]{4}{*}{ Starch } & Cassava & 30 & 40 & 0.35 & 0.6 & 0.4 & 1.5 \\
\hline & Matoke & 470 & 610 & 5.6 & 1.4 & 9.3 & 0.0 \\
\hline & Bread & 10 & 30 & 0.2 & 1.3 & 0.09 & - \\
\hline & Millet & 20 & 60 & 1.0 & 0.2 & 0.9 & 0.7 \\
\hline \multirow[t]{4}{*}{ Protein } & Beans & 210 & 260 & 18.4 & 1.0 & 6.9 & - \\
\hline & Ground-nut sauce & 55 & 170 & 7.6 & 14 & 1.2 & 1.7 \\
\hline & Milk & 230 & 150 & 8.2 & 8.6 & 0.1 & 121 \\
\hline & Meat & 15 & 30 & 2.6 & 2.6 & 0.5 & 3.6 \\
\hline Fat & Cooking oil & 10 & 100 & 0.0 & 0.3 & 0.0 & 0.0 \\
\hline Fruit, & Avocado & 100 & 120 & 1.4 & 11 & 1.4 & 88 \\
\hline \multirow[t]{4}{*}{ Vegetables } & Green vegetables & 40 & 60 & 4.6 & 0.08 & 0.7 & 396 \\
\hline & & Totals & 1630 & 49 & 51 & 21 & 612 \\
\hline & & $\mathrm{RDI}^{*}$ & 1520 & 26 & 42 & 14 & 400 \\
\hline & & Balance & 110 & 23 & 9 & 7 & 212 \\
\hline
\end{tabular}

*RDI = Recommended Daily Intake

of households generally consumed the same amount per day, except for millet and meat, where children in H I V / AIDS affected homes consumed more.

Additional survey findings indicated that $82 \%$ of all children had been sick in the last three months, an average of 1.8 times. Each disease episode lasted on average 13.5 days. This would have led to an average total of $97(13.5 \times 1.8 \times 4)$ sick days per sick child (or being sick $27 \%$ of the time) per year. Seventy three percent of those children were cited to have had fever/malaria, 59\% had cough, and 3\% had suffered from diarrhoea. 


\section{DISCUSSION}

The food frequency nutritional analysis highlights that the children did not suffer from acute food shortages. We only found a calorie deficit in the youngest age group. Western Uganda is generally a very fertile area, rarely afflicted by droughts. This factor may explain the absence of acute clinical malnutrition (which is very visible when it exists). The high rates of stunting (chronic malnutrition) and underweight are less visible and therefore do not draw attention by health workers and the population alike. Stunting was most severe in the age group 1235 months and is likely due to the effects of chronically insufficient intake of calories, possibly as a result of the weaning process, diets based mainly on starch with low energy density, limited amount of beans and fruit/vegetables, and the effects, of frequent disease episodes. Most families grew some basic food crops, but due to poverty, families did not have much disposable income needed to purchase additional nutritious foods in the market.

Although the total average protein and iron consumption of the sampled children appear adequate, it must be considered that beans (the main protein source) are an incomplete protein. Beans do not supply all the necessary essential amino acids required. Also iron supplied by non-heme (vegetable) sources is more difficult to absorb compared to heme-iron from animal food sources. Therefore, adequate amounts of "incomplete" protein and non-heme iron could still have resulted in deficiencies in the children. However, the main feeding problem for children between 12-35 months which was documented in our study were carbohydrates (Table 1), as the RDI for protein and fat was sufficient, hence causing a deficit for carbohydrates. This is not surprising, as matoke is the main source for carbohydrates for the children which is bulky and has a low energy density.

Savage-King and Burgess (12) state that their food composition tables do not offer a precise estimation of the energy or nutrient needs for an individual.

The weights and activity levels used in the food composition tables are similar to those in many tropical, low-income countries, but nutrient and energy requirements vary greatly between individuals. Illness is a factor that greatly increases the body's energy requirements. The calculations used to estimate the average TEE for children in this study were based on the assumption that children were healthy, and free from disease or malnutrition. It is apparent that this assumption is incorrect. Therefore, it must be considered that the TEE values are underestimations of these children's "true" TEE need. The RDI values used in this analysis are likely gross underestimations when considering the frequent disease episodes experienced by the majority of the children under study.

There was little difference in the nutritional intake of young children in AIDS affected homes versus nonAIDS affected homes in this study, with the exception that millet and meat consumption was higher in children living in HIV/AIDS affected homes. The higher meat consumption in those children is difficult to explain. One would expect the opposite, assuming that resources in households with an AIDS patients are more limited (cash, labour) because of care related responsibilities. However, it has been reported from this area that family caregivers, who care for the AIDS patients at home, make all efforts to satisfy the nutritional demands for their AIDS patients by using household savings to buy additional food. Therefore, it could be possible that more meat is available in those families, not only for the AIDS patients but also for the other family members including children. In contrast to these two exceptions, our study findings generally indicate, that children in HIV/AIDS affected homes are equally fed as the children in HIV negative homes.

Limitations of this study include the possibility that there may have been some HIV positive children, which would have affected their nutritional status and / or nutritional intake. There may have been also misclassification of non-AIDS affected homes, if families were afraid to disclose their status. AIDS affected homes were selected from a population using support services which may have caused a selection bias. Non-users of services are usually different from users (usually poorer and less informed). Secondly, breast feeding was not measured, but as it was practiced in only 20 children, therefore we believe that it did not influence the study results in any significant way. Recall bias in the food frequency questionnaire is possible. There are also limitations in the accuracy of the estimation of food portion sizes. It is most probable that the food frequency results are over-estimations of children's dietary intake. 


\section{CONCLUSIONS AND IMPLICATIONS}

The extremely high rates of chronic malnutrition in this area highlight a great need for attention and action directed at improving the nutritional status of children in Uganda. According to our study results, a focus for action should be placed on the youngest children between the ages of one to three years and their seriously deficient energy requirements. Chronic malnutrition with frequent disease episodes not only place these children at risk for mortality, but may also lead to serious long-term deficits in their mental and physical growth and development. Malnourished children will be more likely to have less intellectual capacity and will have a shorter stature, both of which affect their wellbeing and adult life productivity (14). The lifelong ramifications of childhood malnutrition may also negatively impact the health and socio-economic functioning of communities at large and the country as a whole.

As nutrition is a basic building block of a healthy society, there is an urgent need to address the complex factors diminishing the nutritional status of children in Uganda. Poverty plays a key role in this situation, but there are cost-effective interventions locally available to reduce chronic malnutrition in children. It may require shifting food production to more nutritious foods and foods that are new for this area such as orange fleshed sweet potatoes with higher energy density and protein rich beans. The possibility that families can produce healthy foods and raise healthy young children without external assistance is important to empower women and families. A thorough cultural understanding of family practices around food production and consumption must be the underpinnings of a comprehensive strategy to address child malnutrition which remains a basic public health problem in Uganda.

\section{ACKNOWLEDGEMENTS}

To Jean Kipp for her comments on the first draft of the manuscript. The study was funded by the Canadian International Development Agency (CIDA), Ottawa, Canada; grant number S098/S4074-350.

\section{REFERENCES}

1. Foster G. Today's children: Challenges to child health promotion in countries with severe AIDS epidemics. AIDS Care. 1998; 10(Suppl. 1): 17-24.

2. Hunter S. and Williamson J. Children on the brink: Strategies to support children isolated by HIV / AIDS. US Agency for International Development [On-line]. Available: www.synergyaids.com/children/htm, 1997.

3. Adetunji J. Trends in under-five mortality rates and the HIV / AIDS epidemic. Bull. WHO. 2000; 78: 1200-1206.

4. Wekesa E. The impact of HIV/AIDS on child survival and development in Kenya. AIDS Analys. Afr. 2000; 10: 12-14.

5. The Republic of Uganda Ministry of Health. Annual Health Sector Performance Report. Kampala, September 2001.

6. Owor M., Tumwine J.K. and Kikafunda J.K. Socioeconomic risk factors for severe protein energy malnutrition among children in Mulago Hospital, Kampala. East Afr. Med. J. 2000; 77: 471-475.

7. Vella V., Tomkins A., Borghesi A., Migiliori G.B., Ndiku J. and Charles B. Anthropometry and childhood mortality in Northwest and Southwest Uganda. Amer. J. Pub. Hlth. 1993; 83: 1616-1618.

8. World Health Organization. WHO global database on child growth and malnutrition [On-Iine]. Available: http:/ /www.who.int/gdgm/p-child pdf/uga.pdf, 2005.

9. Seeley J. and Kajura E. The extended family and support for people with AIDS in a rural population in South West Uganda: A safety net with holes? AIDS Care. 1993; 5: 117-123.

10. Bridge A., Kipp W., Jhangri G., Laing L. and Konde-Lule J. Nutritional status of young children in HIV/AIDS affected homes and controls in Uganda. Amer. J. Trop. Med. Hyg. 2006; 74: 926-931.

11. Samour P.Q., Helm K.K. and Lang C.E. Handbook of Pediatric Nutrition (2 ${ }^{\text {nd }}$ Ed.). Gaithersburg M.A. Aspen Publishers, Inc., 1999.

12. Savage-King F. and Burgess A. Nutrition for Developing Countries (2 ${ }^{\text {nd }}$ Ed.). New York: Oxford University Press, 1993.

13. World Health Organization, 1995. Physical status: The use of and interpretation of anthropometry. Geneva, Switzerland.

14. Murphy A., Grajeda R., Maluccio J.A., Melgar P., deBarrios A. and deTejada S.S. Social and economic development and change in four Guatemalan villages: Infrastructure, services and livelihood. Instituto de Nutricion de Centro America y Panama (INCAP) 2005, publication $\mathrm{MI} / 007$, www.bvssan.incap.org. 